\title{
Effect of Ivabradine on Left Ventricular Diastolic Function, Exercise Tolerance and Quality of Life in Patients With Heart Failure: A Systemic Review and Meta-Analysis of Randomized Controlled Trials
}

\author{
Theresa Ruba Koroma ${ }^{a}$, Sallieu Kabay Samurab, \\ Yuguo Cheng ${ }^{\mathrm{a}}$, Mengxiong Tang, c
}

\begin{abstract}
Background: Ivabradine is a heart rate-lowering drug that selectively inhibits the funny $\left(\mathrm{I}_{\mathrm{f}}\right)$ current of the sinoatrial node. It is currently recommended in patients with heart failure (HF) with reduced ejection fraction (HFrEF) in sinus rhythm and a heart rate of $\geq 70$ beats per minute (bpm) at rest. To investigate whether ivabradine has an effect on diastolic dysfunction, exercise tolerance and quality of life (QOL), we conducted a systemic review and meta-analysis of randomized controlled trials (RCTs).
\end{abstract}

Methods: We searched PubMed, EMBASE and Cochrane Central Register of Clinical Trials for studies on the effect of ivabradine on left ventricular (LV) diastolic dysfunction, exercise tolerance, QOL, readmission for worsening $\mathrm{HF}$ and mortality in both patients with $\mathrm{HF}$ with preserved ejection fraction (HFpEF) and HFrEF.

Results: Thirteen RCTs with 881 patients met the inclusion criteria. According to the pooled analysis, for the HFpEF subgroup, treatment with ivabradine resulted in a decrease in early diastolic mitral inflow to late diastolic flow ratio (E/A) (standardized mean difference (SMD): -0.53 ; 95\% confidence interval $(\mathrm{CI}):-0.99,-0.07$; $\mathrm{P}<0.000)$ and increase in peak oxygen uptake during exercise $\left(\mathrm{VO}_{2}\right)(\mathrm{SMD}: 0.05 ; 95 \%$ CI: $\left.-0.35,0.45 ; \mathrm{P}<0.00 ; \mathrm{I}^{2}=95.1 \%\right)$. Similar effect was seen in the HFrEF subgroup with decrease in E/A ratio (SMD: -0.33 ; 95\% CI: $-0.59,-0.06 ; \mathrm{P}<0.000)$ and early diastolic mitral inflow to annular velocity ratio (E/e') (SMD: -1.01 ; 95\% CI: $-1.49,-0.54 ; \mathrm{P}<0.012$ ). Ivabradine therapy increased peak $\mathrm{VO}_{2}$ and 6-min walk test (6MWT) in HFrEF patients (SMD: 0.83; 95\% CI: 0.35, 1.32; P<0.00; $\mathrm{I}^{2}=$ 97.5\% and SMD: 1.11 ; 95\% CI: 0.82, 1.41; P < 0.000, respectively). There was also significant reduction in Minnesota Living with Heart

Manuscript submitted October 5, 2019, accepted October 17, 2019

${ }^{a}$ Department of Emergency Medicine, Qilu Hospital of Shandong University, Jinan, China

${ }^{\mathrm{b} S}$ School of Mathematical Sciences, Anhui University, Hefei, China

${ }^{c}$ Corresponding Author: Mengxiong Tang, Qilu Hospital of Shandong University, 107 Wenhua W. Road, Lixia District, Jinan, China.

Email: mengxiongtang@hotmail.com

doi: https://doi.org/10.14740/cr958
Failure Questionnaire (MLHFQ) score (SMD: -0.68; 95\% CI: -0.91, $-0.45 ; \mathrm{P}<0.000)$. However, there was no significant difference in readmission for worsening $\mathrm{HF}$ and all-cause mortality between ivabradine and control (risk ratio (RR): 1.44 ; 95\% CI: 0.73, 2.16; $\mathrm{P}<0.148$ and RR: 0.76 ; 95\% CI: 0.19, 1.33; P $<0.907$, respectively).

Conclusions: Ivabradine therapy is associated with improved LV diastolic function, increases exercise tolerance and hence QOL, but it has no significant effect on readmission for worsening HF and allcause mortality.

Keywords: Ivabradine; Heart failure with preserved ejection fraction; Heart failure with reduced ejection fraction; Diastolic dysfunction; Exercise intolerance; Quality of life

\section{Introduction}

Heart failure (HF) is a compound clinical syndrome, comprising of a constellation of signs and symptoms portraying a reduction in cardiac output and/or increased in pressures in the heart chambers. Depending on left ventricular ejection fraction (LVEF), HF can be classified into HF with preserved ejection fraction (HFpEF), HF with mid-range ejection fraction (HFmrEF), and HF with reduced ejection fraction (HFrEF) [1]. There has been significant improvement in the treatment of cardiac diseases in the past few decades, but HF remains a serious public health issue because of its rising prevalence $[2,3]$ and poor prognosis [4]. It is well known that elevated heart rate (HR) is an independent risk factor for cardiovascular morbidity and mortality [5-7]. A high HR increases myocardial demand, decreases myocardial blood supply and oxygen $\left(\mathrm{O}_{2}\right)$ delivery, shortens the diastolic filling time and increases cardiac filling pressures which consequently lead to a decrease in exercise capacity. In a recent study, an increase in LV diastolic pressure was observed in both patients with HFrEF and HFpEF [8]. Exercise intolerance in the form of dyspnea is one of the main symptoms of HF [1,9], and it is of uttermost importance because it is related to poor quality of life (QOL) [10] and increased mortality. Currently there is no drug that has shown to 
have a significant effect on diastolic dysfunction or improved survival in diastolic HF. Therefore a therapeutic agent targeted at improving diastolic function and resultant increase in exercise tolerance in these patients is needed.

Ivabradine is a HR-lowering drug that selectively blocks the funny $\left(I_{f}\right)$ channels of the sinoatrial node thereby decreasing the pacemaker current. It is currently recommended in patients with HFrEF in sinus rhythm and a HR of $\geq 70$ beats per minute (bpm) at rest despite optimum treatment with other standard therapy. Several studies have reported the effect of ivabradine on HR reduction, but not much is known about its effect on diastolic dysfunction and exercise tolerance. Some experiment studies however have demonstrated improvement of LV diastolic function and reduction in cardiac remodeling by $I_{f}$ blockade $[11,12]$. Accordingly, the aim of this meta-analysis is to investigate the effect of ivabradine on LV diastolic dysfunction, exercise capacity and QOL.

\section{Materials and Methods}

This study was conducted in line with the preferred reporting items for systemic reviews and meta-analysis (Preferred Reporting Items for Systematic Reviews and Meta-Analyses (PRISMA)) [13].

\section{Literature search and selection}

Two independent researchers (TRK and SKS) identified studies by searching the electronic databases of PubMed, EMBASE and Cochrane Central Register of Clinical Trials for studies on the effect of ivabradine on LV diastolic dysfunction, exercise tolerance, QOL of patients with HF (HFrEF and HFpEF).

Studies were included in this meta-analysis if they: 1) were randomized controlled trials (RCTs); 2) compared ivabradine treatment with standard medical care or other control group; 3 ) study population is adult ( $>18$ years) with $\mathrm{HF} ; 4)$ reported one or more of the following outcomes: LV diastolic dysfunction, exercise tolerance and QOL. The exclusion criteria were: 1) non-human studies; 2) articles in a language other than English; 3) abstract and posters.

Primary end points were LV diastolic dysfunction, exercise intolerance and QOL. Secondary endpoints considered were readmission for worsening HF and all-cause mortality. Echocardiographic measures of LV diastolic function which are early diastolic mitral inflow to late diastolic flow ratio (E/A) and early diastolic mitral inflow to annular velocity ratio (E/e') were extracted. The 6 -min walk test (6MWT) and peak oxygen uptake during exercise $\left(\mathrm{VO}_{2}\right)$ were extracted as measurement of exercise tolerance, and Minnesota Living with Heart Failure Questionnaire (MLHFQ) for QOL.

\section{Data extraction and quality assessment}

Data were systematically extracted from text, tables and figures from each study independently by two researchers (TRK and SKS), and tallied in an electronic database. These data included study name, author, year of publication, total number of patient studied and setting of the study, intervention, control, mean age, percentage of sex, mean HR, primary endpoints, clinical efficacy outcomes and duration of follow-up. Any disagreement was settled by discussion and consensus.

\section{Statistical analysis}

We use STATA version 13 for statistical analysis. We calculate Cohen's d standardized mean difference (SMD), risk ratio (RR) for categorical events and 95\% confidence interval (CI). The $\mathrm{I}^{2}$ statistic was used to describe the percentage variability that is due to heterogeneity. Heterogeneity in the eligible studies was evaluated using $\chi^{2}$ test on the basis of Cochrane's $Q$ test and at $\mathrm{P}<0.10$ level of significance. $\mathrm{I}^{2}$ values of $0-25 \%$, $25-50 \%$ and $>50 \%$ were considered to be low, moderate and high heterogeneity, respectively. When $\mathrm{P}$ for the heterogeneity is $<0.1$ and $\mathrm{I}^{2} \geq 50 \%$, the inter-study heterogeneity is considered significant. Publication biased was assessed graphically using funnel plot [14] and Egger meta-regression test to detect the potential source of heterogeneity.

\section{Results}

The literature search using key words yielded 881 articles. After removing duplicates and screening for relevancy, 75 articles were remained. Of these, 61 articles were excluded because they didn't meet the inclusion criteria. After a careful and thorough review, one study was excluded because the result was reported in median and not mean \pm standard deviation (SD). A total of $13 \mathrm{RCTs}$ met the criteria of inclusion in this study (Fig. 1). Ten studies included patients with HFrEF, and four studies included patients with HFpEF.

Characteristics of the included studies on HFpEF are summarized in Table 1 [15-17], and those on HFrEF in Table 2 [18-27]. A total of 821 patients were enrolled in the 13 included RCTs with duration of follow-up ranging from 7 days to 6 months. There were $125 \mathrm{HFpEF}$ in three studies and 696 HFrEF in 10 studies. The funnel plot of all studies demonstrates that there is low risk of publication bias (Fig. 2). Eggers regression test shows that (coefficient: -4.091 ; 95\% CI: $-6.359485,-1.821423 ; \mathrm{P}=0.007)$. For the primary end point of interest in the HFpEF group, two studies reported on the effect of ivabradine on change in $\mathrm{E} / \mathrm{A}$, three on $\mathrm{E} / \mathrm{e}$ ' ratio, two on peak $\mathrm{VO}_{2}$, and one on 6MWT. In the HFrEF group, three studies reported on the effect of ivabradine on change in E/A, two on $\mathrm{E} / \mathrm{e}$ ' ratio, three on peak $\mathrm{VO}_{2}$, three on $6 \mathrm{MWT}$ and seven reported on QOL (MLHFQ score). For the secondary endpoints, three studies reported on hospital admission for worsening $\mathrm{HF}$, and five studies over all reported on all-cause mortality.

\section{Effect of ivabradine on diastolic dysfunction}

As shown in Figure $3 a$ and $b$, in the HFpEF subgroup, there 


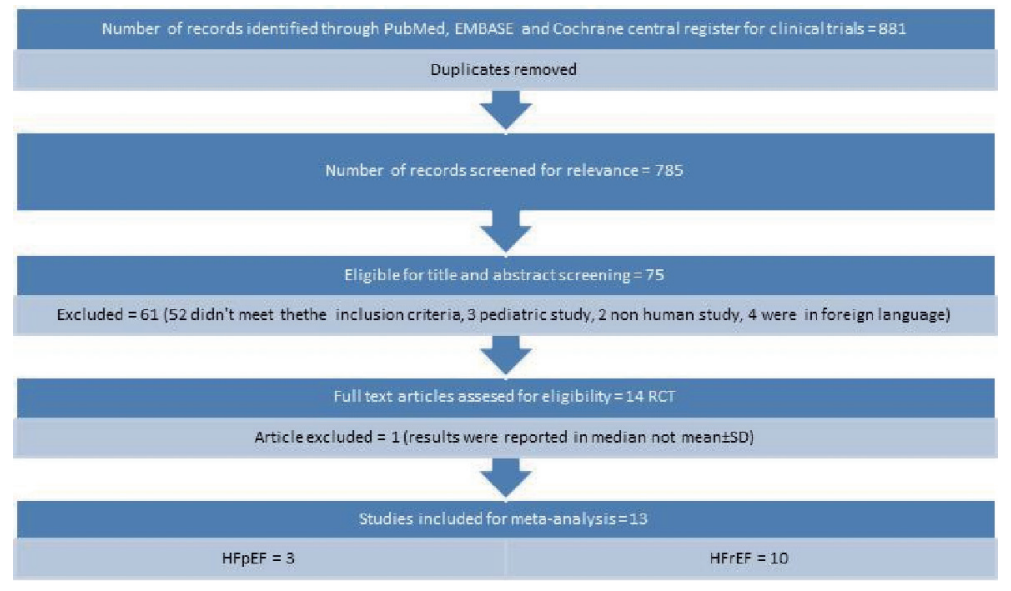

Figure 1. Flow diagram for studies included in the meta-analysis.

was significant reduction in E/A ratio (SMD: -0.53 ; 95\% CI: $-0.99,-0.07 ; \mathrm{P}<0.000 ; \mathrm{I}^{2}=94.9 \%$ ) in the ivabradine group compared to control. E/e' ratio was significantly increased in the control group (SMD: 0.95; 95\% CI: 0.62, 1.27; P < 0.000; $\left.\mathrm{I}^{2}=96.5 \%\right)$.

For the HFrEF subgroup, there was significant reduction in both $\mathrm{E} / \mathrm{A}$ ratio (SMD: -0.33 ; 95\% CI: $-0.59,-0.06$; $\mathrm{P}<$ $0.000 ; \mathrm{I}^{2}=88.5 \%$ ) and E/e' ratio (SMD: $-1.01 ; 95 \% \mathrm{CI}:-1.49$, $\left.-0.54 ; \mathrm{P}<0.012 ; \mathrm{I}^{2}=84.1 \%\right)$ in the ivabradine group compared to control (Fig. 3c and d).

\section{Effect of ivabradine on exercise tolerance and QOL}

For the HFpEF subgroup, peak $\mathrm{VO}_{2}$ was significantly higher with ivabradine therapy than control (SMD: 0.05 ; 95\% CI: $-0.35,0.45 ; \mathrm{P}<0.00 ; \mathrm{I}^{2}=95.1 \%$ ) (Fig. 4a). For the HFrEF subgroup (Fig. $4 \mathrm{~b}$ and c), peak $\mathrm{VO}_{2}$ and $6 \mathrm{MWT}$ were significantly higher with ivabradine therapy than control (SMD: $0.83 ; 95 \%$ CI: $0.35,1.32 ; \mathrm{P}<0.00 ; \mathrm{I}^{2}=97.5 \%$, and SMD: $1.11 ; 95 \% \mathrm{CI}$ : $0.82,1.41 ; \mathrm{P}<0.000 ; \mathrm{I}^{2}=97.4 \%$, respectively). MLHFQ score decreased significantly in the ivabradine group compared to control (SMD: -0.68; 95\% CI: -0.91, -0.45; P < 0.000; $\mathrm{I}^{2}=$ 97.5\%) (Fig. 5).

\section{Effect of ivabradine on worsening HF and all-cause mor- tality}

As shown in Figure 6, there was no significant change in worsening $\mathrm{HF}$ and all-cause mortality in response to ivabradine therapy with RR of 1.44 ; 95\% CI: $0.73,2.16$; P $<0.148$; ${ }^{2}$ $=47.7 \%$ and RR of $0.76 ; 95 \%$ CI: $0.19,1.33 ; \mathrm{P}<0.907 ; \mathrm{I}^{2}=$ $0.0 \%$, respectively.

\section{Discussion}

For the heart to function as an effective pump, it has to be able to not only eject (systolic function) but also fill blood (diastolic function) [28]. Diastolic dysfunction is observed in both patients with HFpEF and HFrEF, and it is of clinical importance as it is closely related to symptoms of exercise intolerance and severity of HF [8]. The mainstay of treatment of HF is targeted at reducing the preload and afterload of the heart, and a lot of the big trials for HF management considered improvement in LV systolic parameters, whereas the optimal management for LV diastolic dysfunction is not well known. Ivabradine has been found to be beneficial in the management of HFrEF because of its HR-reducing effect. For example, in the recent multinational Systolic Heart Failure Treatment with the $I_{f}$ inhibitor Ivabradine Trial (SHIFT) [29] in 6,505 patients with $\mathrm{HF}$, ivabradine therapy was shown to have reduced the risk for the primary composite endpoint of cardiovascular death and readmission for worsening $\mathrm{HF}$ by $18 \%$. While this was one of the backgrounds for including ivabradine to the guidelines for management of HFrEF, the SHIFT study did not assess the effect of HR reduction by ivabradine on change in diastolic dysfunction and symptoms of HF.

The result of our meta-analysis demonstrates that the use of ivabradine resulted in improvement in the primary outcome stated earlier. In the HFpEF group, there was a statistically significant improvement in diastolic function with decrease in $\mathrm{E} / \mathrm{A}$ ratio, increase in exercise tolerance as seen in increase in peak $\mathrm{VO}_{2}$ with ivabradine therapy compared with control.

For the HFrEF group, with ivabradine therapy, there was significant improvement in diastolic function with decrease in $\mathrm{E} / \mathrm{A}$ ratio and $\mathrm{E} / \mathrm{e}$ ' ratios, increase in exercise tolerance as seen in longer distance covered during 6MWT and an increase in peak $\mathrm{VO}_{2}$ compared with control. Also with ivabradine therapy there was an improvement in QOL evident by a reduction in MLHFQ score. However, there was no significant change in hospitalization for worsening HF and all-cause mortality when treated with ivabradine.

The major finding of this study was that ivabradine therapy improved diastolic function by decreasing LV filling pressures in both HFpEF and HFrEF. Cardiac output is a product of stroke volume and HR. In a patient with HF with an impaired stroke volume, there is a compensatory increase in HR 


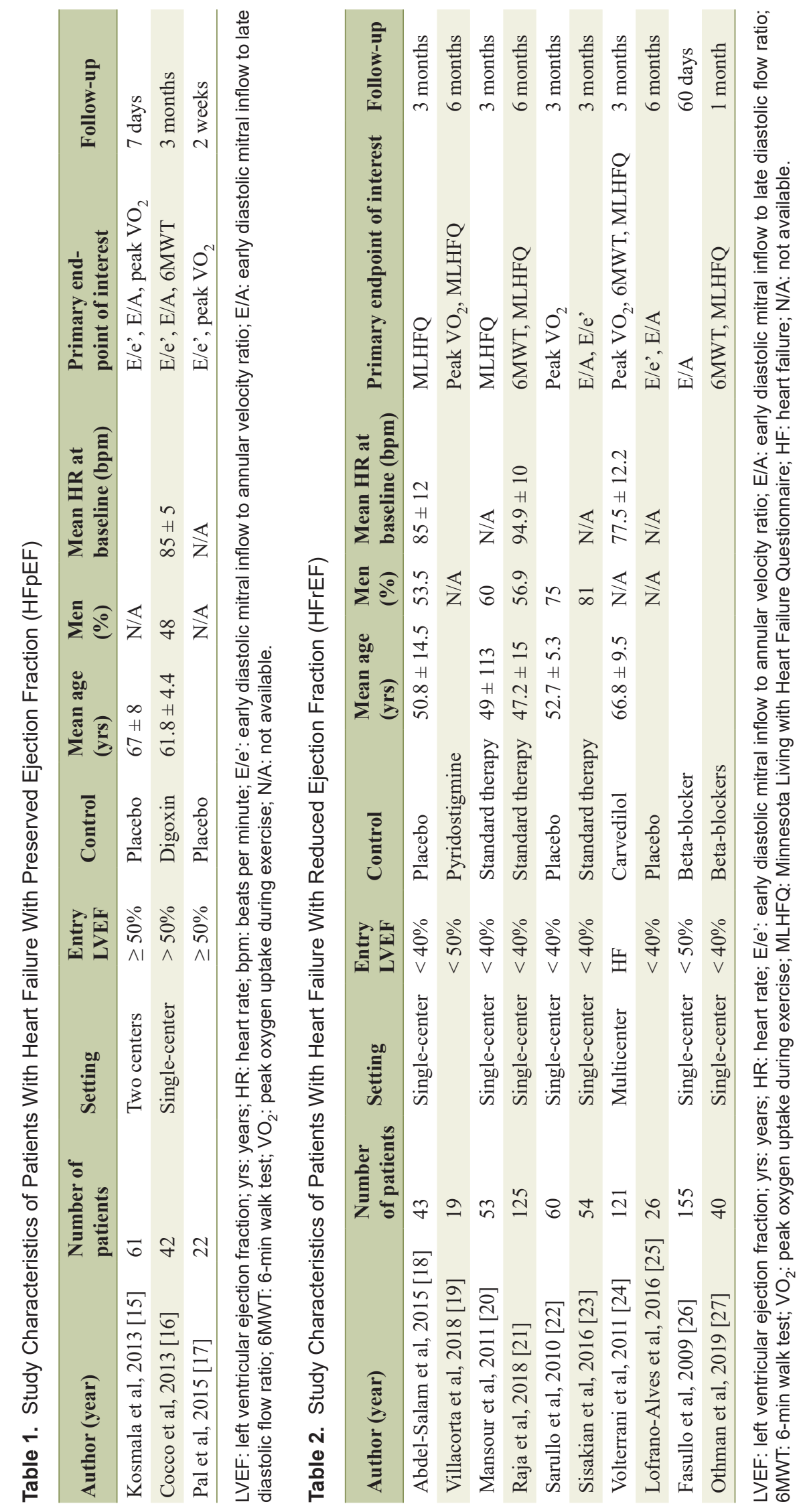




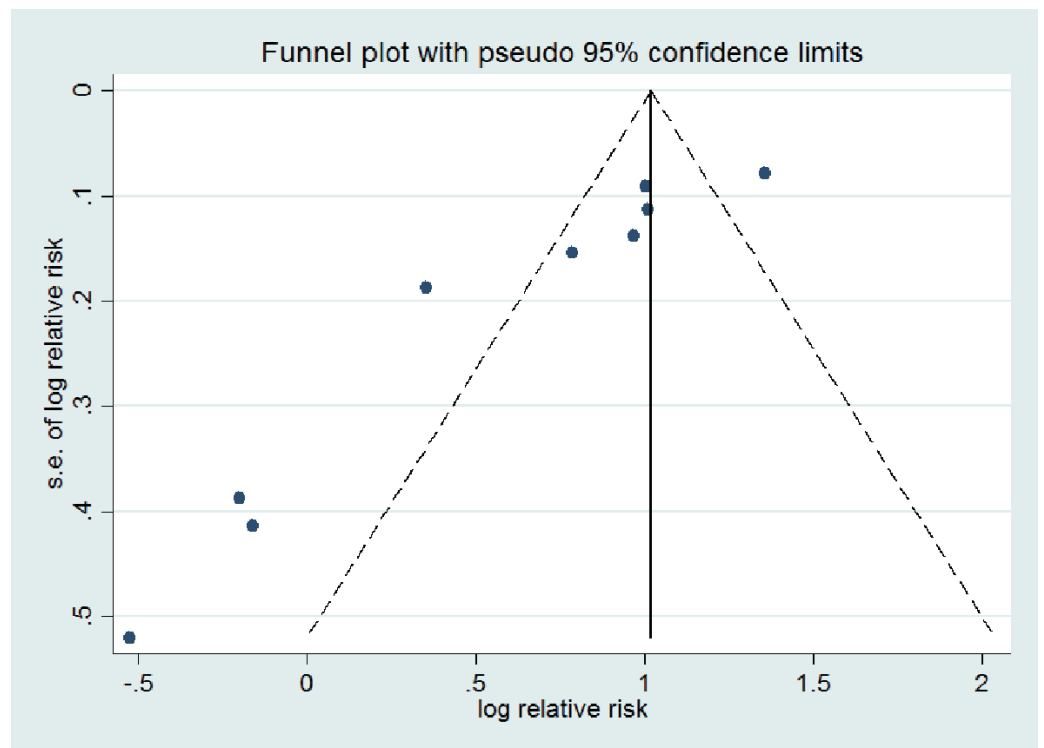

Figure 2. Funnel plot of relative risk versus standard error.

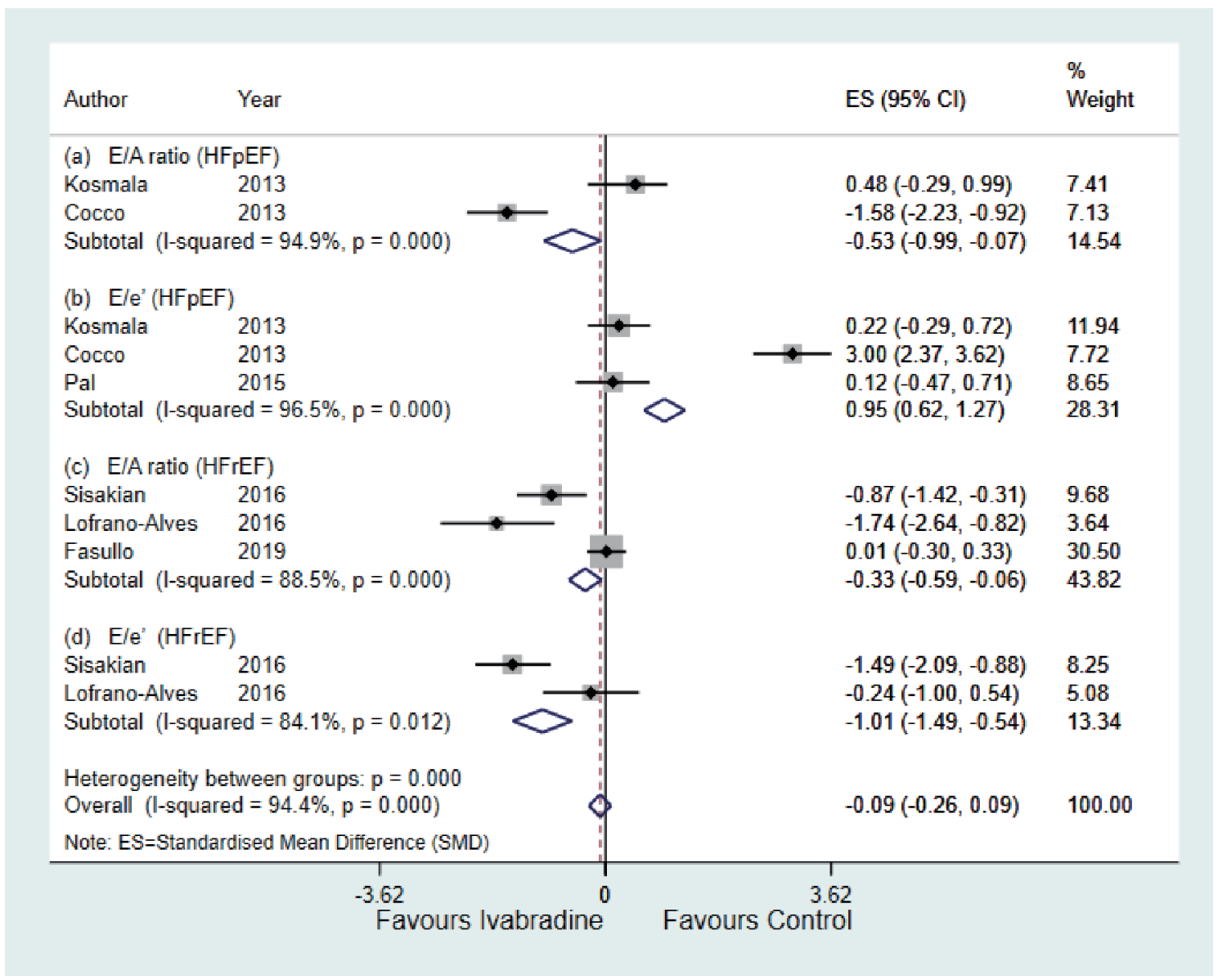

Figure 3. Forest plot showing the effect of ivabradine on diastolic echocardiographic parameters compared with control in patients with HFpEF and HFrEF; change in E/A, and change in E/e'. E/e': early diastolic mitral inflow to annular velocity ratio; E/A: early diastolic mitral inflow to late diastolic flow ratio; HFpEF: heart failure with preserved ejection fraction; HFrEF: heart failure with reduced ejection fraction; $\mathrm{Cl}$ : confidence interval. 


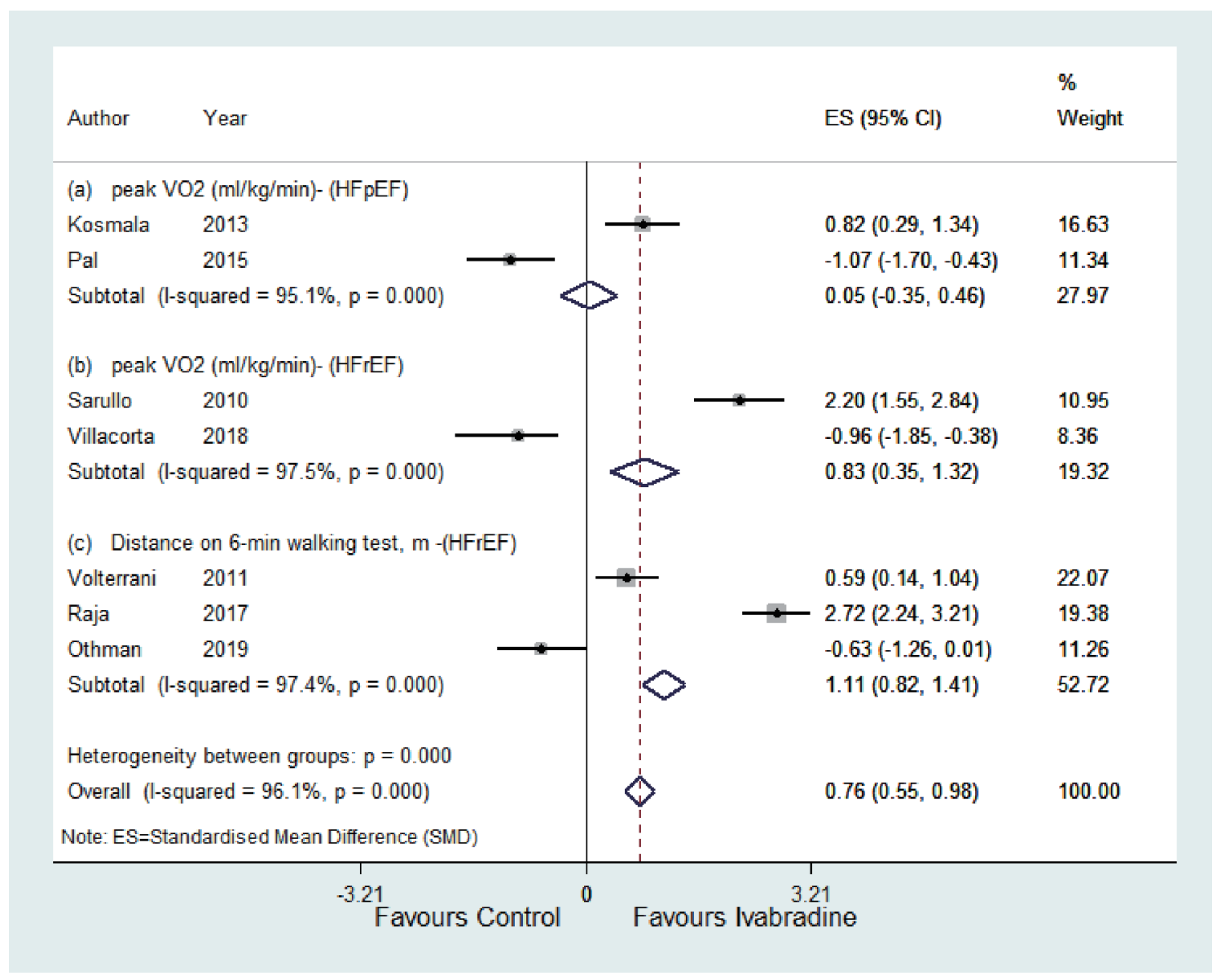

Figure 4. Forest plot showing the effect of ivabradine on exercise tolerance (peak $\mathrm{VO}_{2}(\mathrm{mg} / \mathrm{kg} / \mathrm{min})$, distance on 6-min walking test $(\mathrm{m})$ ) compared with control in patients with $\mathrm{HFpEF}$ and $\mathrm{HFrEF} . \mathrm{VO}_{2}$ : peak oxygen uptake during exercise; HFpEF: heart failure with preserved ejection fraction; HFrEF: heart failure with reduced ejection fraction; $\mathrm{Cl}$ : confidence interval.

to augment cardiac output. Therefore, by lowering HR with ivabradine, it allows the ventricles to have enough time to relax and fill, hence improving LV diastolic function [30]. Despite several studies demonstrating the effect of beta-blockers in $\mathrm{HF}$, there are no large trials on its effect on diastolic dysfunction. One small retrospective study showed improvement of diastolic dysfunction with long-term beta-blocker therapy [31]. Nonetheless, there are no reports regarding the clinical benefit of this improved diastolic dysfunction. Also in addition to its negative chronotropic effect, beta-blockers also have a negative inotropic effect which is in contrast to ivabradine that purely reduces HR without affecting contractility of the cardiac muscles.

Our study also showed that ivabradine therapy improves exercise tolerance and QOL. Exercise intolerance is one of the hallmark symptoms of HF [10], and happens when augmented cardiac output is not sufficient enough to meet the metabolic demands imposed by exercise [32, 33]. During exercise, there is significant demand for oxygen in the metabolizing tissues. In healthy individuals, this demand is met by increasing both systolic and diastolic cardiac properties which combine to increase stroke volume, hence increase in cardiac output without a significant increase in diastolic pressure. However, in a failing heart, stroke volume during exercise increases with increase in LV end diastolic pressure because of diastolic dysfunction, resulting in exercise intolerance (dyspnea), and consequently reduced QOL [8]. Thus improving diastolic function with ivabradine therapy might be a contributing factor to the improvement seen in exercise intolerance.

In our meta-analysis, in contrast to the SHIFT trial, the use of ivabradine was not associated with significant change in readmission for worsening HF and all-cause mortality. Our findings however are consistent with a recent meta-analysis on the effect of ivabradine on patients with HFrEF by Hartmann et al [34], which showed that ivabradine significant decreased HR but had no effect on worsening HF or all-cause mortality. This can be explained by: 1) The studies included in our meta-analysis were relative smaller in comparison to the SHIFT study; and 2) The follow-up duration was shorter in our included study (ranges from 7 days to 6 months). So it will be inappropriate to report on long-term effect like all-cause mortality with relatively short follow-up.

While this study has its strengths, there are a few weaknesses to mention. Firstly, there were few RCTs that were eligible for inclusion in this study, and most of them had small population of patients. Secondly, even though the study con- 


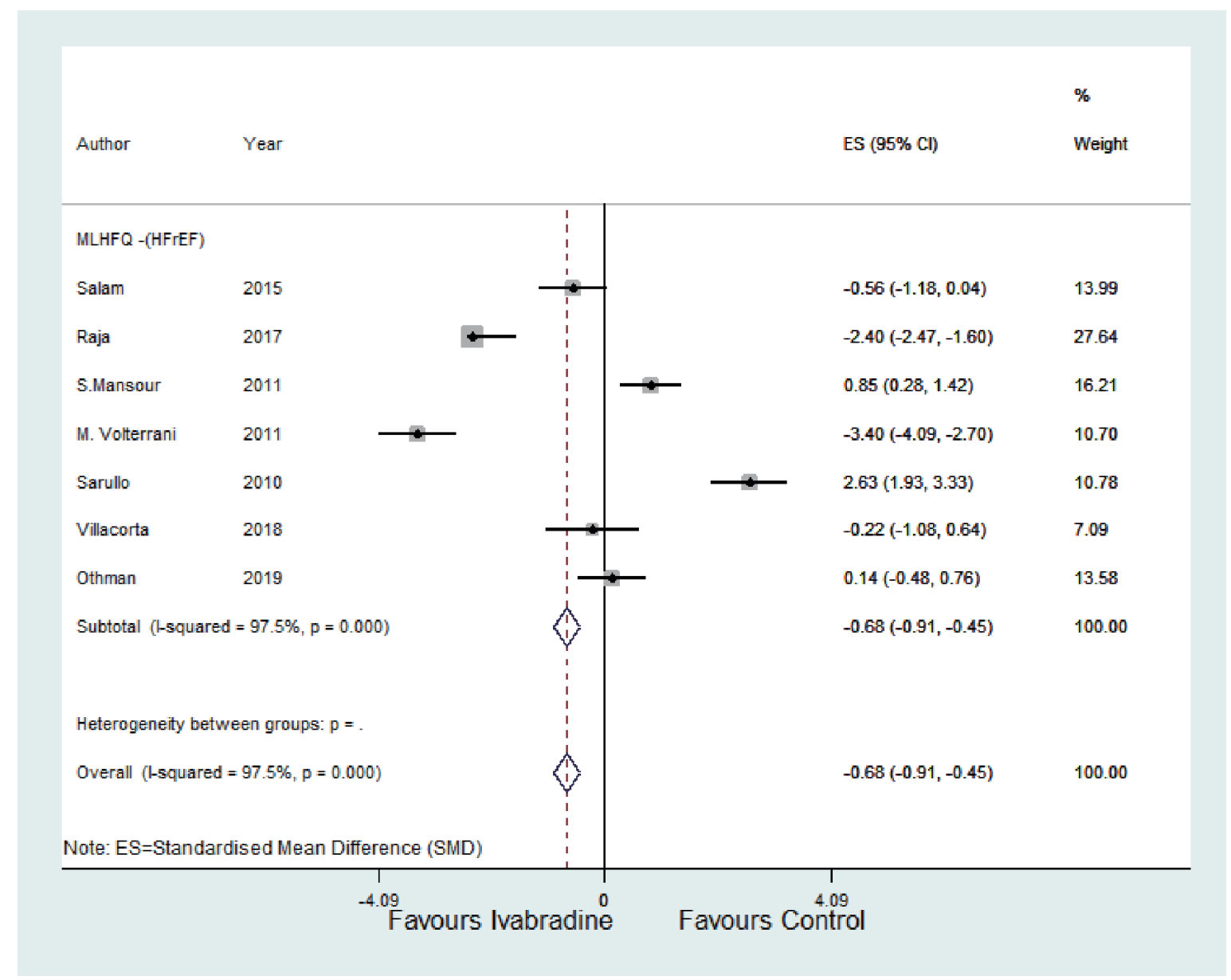

Figure 5. Forest plot showing the effect of ivabradine on QOL (using MLHFQ score) compared with control. HFrEF: heart failure with reduced ejection fraction; Cl: confidence interval; MLHFQ: Minnesota Living with Heart Failure Questionnaire; QOL: quality of life.

sists of 13 RCTs, our primary outcomes of interest unfortunately were not consistently reported in all the studies. Therefore, larger RCTs are needed to validate results. Finally, there was high heterogeneity between the included studies because of population size and duration of follow-up. So to confirm the validity of the result of the present meta-analysis, we performed an Egger regression test.

To the best of our knowledge, this study is the first metaanalysis to demonstrate the effect of ivabradine on diastolic dysfunction, exercise tolerance and QOL.

In conclusion, ivabradine treatment has a positive effect on improving LV diastolic function by reducing E/A ratio in both patients with HFpEF and HFrEF, which is clinically relevant as it plays an integral role in the progression of HF [35]. This improvement translates to improvement of exercise tolerance and QOL. It however has a neutral effect on readmission for worsening HF and mortality.

\section{Acknowledgments}

None to declare.

\section{Financial Disclosure}

The National Natural Science Foundation of China 81670411.

\section{Conflict of Interest}

The authors report no relationship that could be construed as a conflict of interest.

\section{Informed Consent}

Not applicable.

\section{Author Contributions}

Theresa Ruba Koroma contributed to conception and design of the study, collection, analysis and interpretation of the data, writing and revision of the manuscript. Sallieu Kabay Samura 


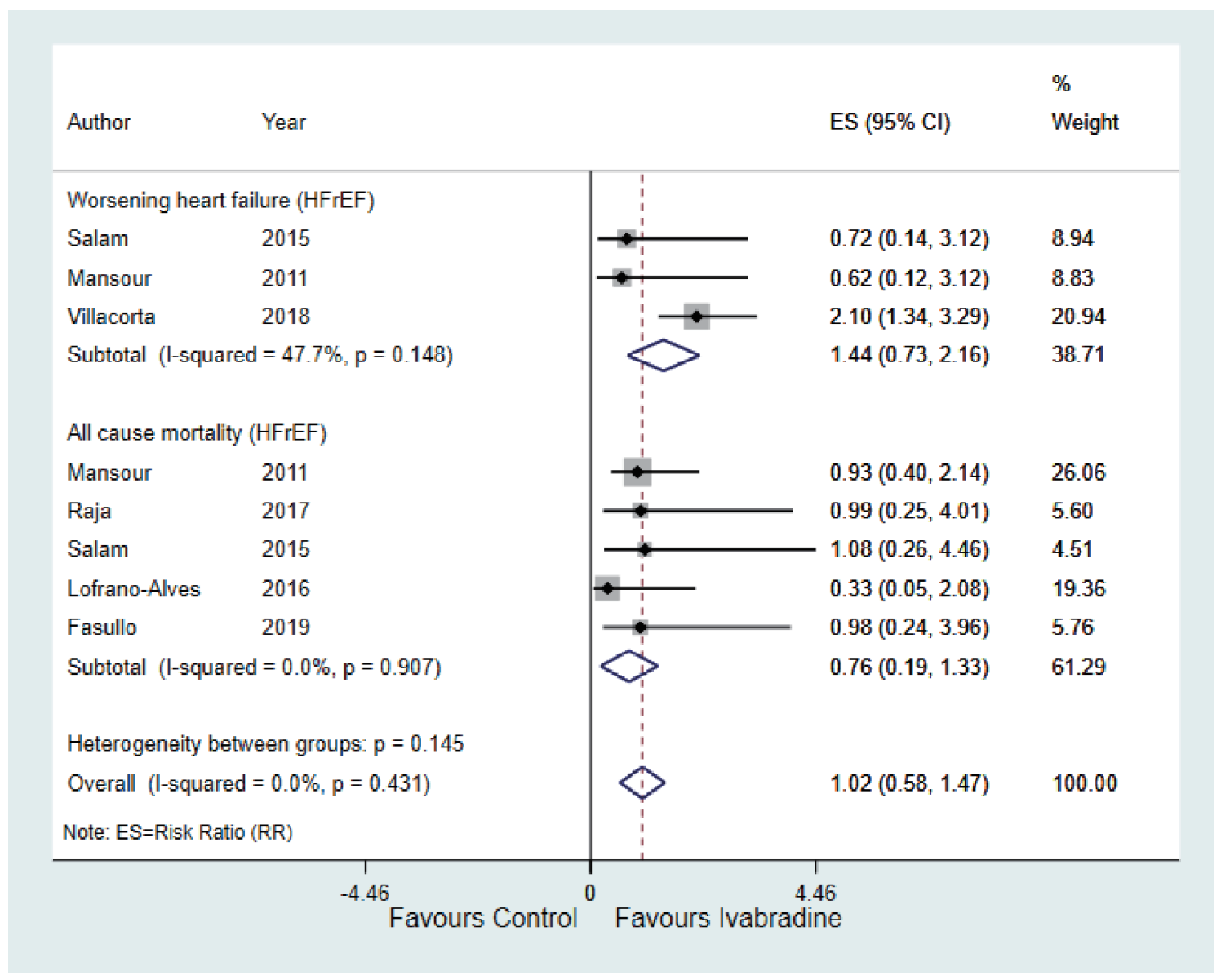

Figure 6. Forest plot showing the effect of ivabradine on worsening heart failure and all-cause mortality. HFrEF: heart failure with reduced ejection fraction; $\mathrm{Cl}$ : confidence interval.

contributed to design of the study, collection, analysis and interpretation of the data and revision of the manuscript. Yuguo Cheng contributed to conception and design of this study, reviewing and editing of the manuscript. Mengxiong Tang contributed to conception and design of the study, reviewing and editing of the manuscript.

\section{References}

1. Ponikowski P, Voors AA, Anker SD, Bueno H, Cleland JG, Coats AJ, Falk V, et al. 2016 ESC Guidelines for the diagnosis and treatment of acute and chronic heart failure: The Task Force for the diagnosis and treatment of acute and chronic heart failure of the European Society of Cardiology (ESC). Developed with the special contribution of the Heart Failure Association (HFA) of the ESC. Eur J Heart Fail. 2016;18(8):891-975.

2. Braunwald E. Heart failure. JACC Heart Fail. 2013;1(1):120.

3. Anguita Sanchez M, Crespo Leiro MG, de Teresa Galvan E, Jimenez Navarro M, Alonso-Pulpon L, Muniz Garcia J, Investigators PS. Prevalence of heart failure in the Spanish general population aged over 45 years. The
PRICE Study. Rev Esp Cardiol. 2008;61(10):1041-1049.

4. Bleumink GS, Knetsch AM, Sturkenboom MC, Straus SM, Hofman A, Deckers JW, Witteman JC, et al. Quantifying the heart failure epidemic: prevalence, incidence rate, lifetime risk and prognosis of heart failure The Rotterdam Study. Eur Heart J. 2004;25(18):1614-1619.

5. Diaz A, Bourassa MG, Guertin MC, Tardif JC. Longterm prognostic value of resting heart rate in patients with suspected or proven coronary artery disease. Eur Heart J. 2005;26(10):967-974.

6. Kannel WB, Kannel C, Paffenbarger RS, Jr., Cupples LA. Heart rate and cardiovascular mortality: the Framingham Study. Am Heart J. 1987;113(6):1489-1494.

7. Fox K, Borer JS, Camm AJ, Danchin N, Ferrari R, Lopez Sendon JL, Steg PG, et al. Resting heart rate in cardiovascular disease. J Am Coll Cardiol. 2007;50(9):823-830.

8. Zile MR, Kjellstrom B, Bennett T, Cho Y, Baicu CF, Aaron MF, Abraham WT, et al. Effects of exercise on left ventricular systolic and diastolic properties in patients with heart failure and a preserved ejection fraction versus heart failure and a reduced ejection fraction. Circ Heart Fail. 2013;6(3):508-516.

9. Del Buono MG, Arena R, Borlaug BA, Carbone S, Canada JM, Kirkman DL, Garten R, et al. Exercise intoler- 
ance in patients with heart failure: JACC state-of-the-art review. J Am Coll Cardiol. 2019;73(17):2209-2225.

10. Kitzman DW, Little WC, Brubaker PH, Anderson RT, Hundley WG, Marburger CT, Brosnihan B, et al. Pathophysiological characterization of isolated diastolic heart failure in comparison to systolic heart failure. JAMA. 2002;288(17):2144-2150.

11. Busseuil D, Shi Y, Mecteau M, Brand G, Gillis MA, Thorin E, Asselin C, et al. Heart rate reduction by ivabradine reduces diastolic dysfunction and cardiac fibrosis. Cardiology. 2010;117(3):234-242.

12. Fang Y, Debunne M, Vercauteren M, Brakenhielm E, Richard V, Lallemand F, Henry JP, et al. Heart rate reduction induced by the if current inhibitor ivabradine improves diastolic function and attenuates cardiac tissue hypoxia. J Cardiovasc Pharmacol. 2012;59(3):260-267.

13. Liberati A, Altman DG, Tetzlaff J, Mulrow C, Gotzsche PC, Ioannidis JP, Clarke M, et al. The PRISMA statement for reporting systematic reviews and meta-analyses of studies that evaluate healthcare interventions: explanation and elaboration. BMJ. 2009;339:b2700.

14. Duval S, Tweedie R. Trim and fill: A simple funnel-plotbased method of testing and adjusting for publication bias in meta-analysis. Biometrics. 2000;56(2):455-463.

15. Kosmala W, Holland DJ, Rojek A, Wright L, PrzewlockaKosmala M, Marwick TH. Effect of If-channel inhibition on hemodynamic status and exercise tolerance in heart failure with preserved ejection fraction: a randomized trial. J Am Coll Cardiol. 2013;62(15):1330-1338.

16. Cocco G, Jerie P. Comparison between ivabradine and low-dose digoxin in the therapy of diastolic heart failure with preserved left ventricular systolic function. Clin Pract. 2013;3(2):e29.

17. Pal N, Sivaswamy N, Mahmod M, Yavari A, Rudd A, Singh S, Dawson DK, et al. Effect of selective heart rate slowing in heart failure with preserved ejection fraction. Circulation. 2015;132(18):1719-1725.

18. Abdel-Salam Z, Rayan M, Saleh A, Abdel-Barr MG, Hussain M, Nammas W. I(f) current inhibitor ivabradine in patients with idiopathic dilated cardiomyopathy: Impact on the exercise tolerance and quality of life. Cardiol J. 2015;22(2):227-232.

19. Villacorta AS, Villacorta H, Caldas JA, Precht BC, Porto PB, Rodrigues LU, Neves M, et al. Effects of heart rate reduction with either pyridostigmine or ivabradine in patients with heart failure: a randomized, double-blind study. J Cardiovasc Pharmacol Ther. 2018:24(2):139145.

20. Mansour S, Youssef A, Rayan M, Saleh A. Efficacy of ivabradine in idiopathic dilated cardiomyopathy patients with chronic heart failure. The Egyptian Heart Journal. 2011;63:79-85.

21. Raja DC, Kapoor A, Sinha A, Kashyap S, Khanna R, Kumar S, Garg N, et al. Heart rate manipulation in dilated cardiomyopathy: Assessing the role of Ivabradine. Indian Heart J. 2018;70(2):246-251.

22. Sarullo FM, Fazio G, Puccio D, Fasullo S, Paterna S, Novo S, Di Pasquale P. Impact of "off-label" use of ivabradine on exercise capacity, gas exchange, functional class, quality of life, and neurohormonal modulation in patients with ischemic chronic heart failure. J Cardiovasc Pharmacol Ther. 2010;15(4):349-355.

23. Sisakian H, Sargsyan T, Khachatryan A. Effect of selective heart rate reduction through sinus node $\mathrm{I}<\mathrm{sub}>\mathrm{f}<$ / $\mathrm{sub}>$ current inhibition on severely impaired left ventricular diastolic dysfunction in patients with chronic heart failure. Acta Cardiol. 2016;71(3):317-322.

24. Volterrani M, Cice G, Caminiti G, Vitale C, D'Isa S, Perrone Filardi P, Acquistapace F, et al. Effect of Carvedilol, Ivabradine or their combination on exercise capacity in patients with Heart Failure (the CARVIVA HF trial). Int J Cardiol. 2011;151(2):218-224.

25. Lofrano-Alves MS, Issa VS, Biselli B, Chizzola P, AyubFerreira SM, Bocchi EA. Control of sinus tachycardia as an additional therapy in patients with decompensated heart failure (CONSTATHE-DHF): A randomized, double-blind, placebo-controlled trial. J Heart Lung Transplant. 2016;35(10):1260-1264.

26. Fasullo S, Cannizzaro S, Maringhini G, Ganci F, Giambanco F, Vitale G, Pinto V, et al. Comparison of ivabradine versus metoprolol in early phases of reperfused anterior myocardial infarction with impaired left ventricular function: preliminary findings. J Card Fail. 2009;15(10):856863.

27. Othman KMS, Mostafa MAR, Yosef AE, Abdeltawab AA. Safety and efficacy of off-label use of ivabradine in patients with acute heart failure. J Saudi Heart Assoc. 2019;31(4):179-187.

28. Fukuta H, Little WC. Contribution of systolic and diastolic abnormalities to heart failure with a normal and a reduced ejection fraction. Prog Cardiovasc Dis. 2007;49(4):229240.

29. Swedberg K, Komajda M, Bohm M, Borer JS, Ford I, Dubost-Brama A, Lerebours G, et al. Ivabradine and outcomes in chronic heart failure (SHIFT): a randomised placebo-controlled study. Lancet. 2010;376(9744):875885.

30. Mulder P, Barbier S, Chagraoui A, Richard V, Henry JP, Lallemand F, Renet $\mathrm{S}$, et al. Long-term heart rate reduction induced by the selective I(f) current inhibitor ivabradine improves left ventricular function and intrinsic myocardial structure in congestive heart failure. Circulation. 2004;109(13):1674-1679.

31. Tamaki S, Sakata Y, Mano T, Ohtani T, Takeda Y, Kamimura D, Omori Y, et al. Long-term beta-blocker therapy improves diastolic function even without the therapeutic effect on systolic function in patients with reduced ejection fraction. J Cardiol. 2010;56(2):176-182.

32. Abudiab MM, Redfield MM, Melenovsky V, Olson TP, Kass DA, Johnson BD, Borlaug BA. Cardiac output response to exercise in relation to metabolic demand in heart failure with preserved ejection fraction. Eur J Heart Fail. 2013;15(7):776-785.

33. Bailey CS, Wooster LT, Buswell M, Patel S, Pappagianopoulos PP, Bakken K, White C, et al. Post-exercise oxygen uptake recovery delay: a novel index of impaired cardiac reserve capacity in heart failure. JACC Heart Fail. 2018;6(4):329-339. 
34. Hartmann C, Bosch NL, de Aragao Miguita L, Tierie E, Zytinski L, Baena CP. The effect of ivabradine therapy on heart failure patients with reduced ejection fraction: a systematic review and meta-analysis. Int $\mathrm{J}$ Clin Pharm. 2018;40(6):1443-1453.
35. Smart N, Haluska B, Leano R, Case C, Mottram PM, Marwick TH. Determinants of functional capacity in patients with chronic heart failure: role of filling pressure and systolic and diastolic function. Am Heart J. 2005;149(1):152-158. 